J. Lake Sci. (湖泊科学) , 2016, 28(6): 1361-1370

DOI 10. 18307/2016. 0622

(C) 2016 by Journal of Lake Sciences

\title{
安徽太平湖水库初级生产力时空分布及分析”
}

\author{
冯世敏 ${ }^{1}$, 刘冬燕 ${ }^{1,2 * *}$, 李东京 ${ }^{1}$, 吴明姝 ${ }^{1}$, 熊 莲 $^{1}$, 王俊莉 ${ }^{1}$ \\ (1: 上海师范大学生命与环境科学学院,上海 200234) \\ (2: 上海师范大学城市生态与环境研究中心, 上海 200234)
}

\begin{abstract}
摘 要: 安徽太平湖是 2014 年国家列入的重点保护湖泊之一,鉴于其生物本底资料的缺乏,于 2012 年 11 月至 2014 年 10 月, 从上游至下游选取 H1、H2、H3、H4、H5 共 5 个样点, 采用黑白瓶法对太平湖的初级生产力进行为期 2 年的调查研究. 结果显示, 太平湖水柱毛初级生产力、水柱净初级生产力和水柱呼吸量的平均值分别为 $4.54 \pm 6.72 、-1.82 \pm 7.77$ 和 $6.50 \pm$ $7.62 \mathrm{~g} /\left(\mathrm{m}^{2} \cdot \mathrm{d}\right)$. 时间分布上, 水柱毛初级生产力出现 3 个峰值, 分别在 2012 年 11 月、2013 年 5 月和 2014 年 7 月, 呼吸 量在 2013 年 7 月份出现远高于其他月份的峰值, 达到了 $16.04 \mathrm{~g} /\left(\mathrm{m}^{2} \cdot \mathrm{d}\right)$, 水柱毛初级生产力季节变化表现为夏季>秋季> 春季>冬季. 太平湖初级生产力存在显著的空间差异, 水平分布上毛初级生产力与呼吸量的水平分布相似, 湖心 $\mathrm{H} 3$ 样点 最小, 下游的 H4、H5 样点较高; 垂直分布显示, 毛初级生产力主要贡献在表层和 1SD 层, 并沿水深逐渐降低, 呼吸量的垂 直分布与毛初级生产力不同, 最高值出现在 $1 \mathrm{SD}$ 和 $2 \mathrm{SD}$ 层, 各层净初级生产力的值均较小, 无明显峰值或谷值. 研究表 明, 太平湖水库水柱的 $P / R$ 系数小于 1 , 但最高生产力层 (表层) 的 $P / R$ 系数大于 1 . 相关分析显示水柱毛初级生产力与温 度和湖深呈显著正相关, 与其它环境因子相关性不明显.
\end{abstract}

关键词: 太平湖; 初级生产力; $P / R$ 系数; 叶绿素 $\mathrm{a}$; 相关分析

\section{Analysis on the temporal and spatial distribution of the primary productivity and its influen- cing factors in Lake Taiping(Reservoir), Anhui Province}

\author{
FENG Shimin ${ }^{1}$, LIU Dongyan ${ }^{1,2 * *}$, LI Dongjing ${ }^{1}$, WU Mingshu ${ }^{1}$, XIONG Lian $^{1} \&$ WANG Junli ${ }^{1}$ \\ (1: College of Life and Environmental Science, Shanghai Normal University, Shanghai 200234, P.R.China) \\ (2: Urban Ecology and Environment Research Centre, Shanghai Normal University, Shanghai 200234, P.R.China)
}

\begin{abstract}
Lake Taiping in Anhui was one of the protected lakes proposed by China. Given its lack of biological background data, we studied primary productivity of Lake Taiping from November 2012 to October 2014. Five regions from upstream to downstream ( H1 , H2 , H3 , H4, H5) were selected for the measurements of the primary productivity with the dark and white bottle method. Results showed that the gross primary productivity, the net primary productivity and the respiratory capacity of a water column in the lake were $4.54 \pm 6.72 \mathrm{~g} /\left(\mathrm{m}^{2} \cdot \mathrm{d}\right), 1.82 \pm 7.77 \mathrm{~g} /\left(\mathrm{m}^{2} \cdot \mathrm{d}\right)$ and $6.50 \pm 7.62 \mathrm{~g} /\left(\mathrm{m}^{2} \cdot \mathrm{d}\right)$, respectively. As for the time distribution, the gross primary productivity appeared three peaks, in November 2012, May 2013 and July 2014, respectively. Respiratory capacity was much higher than other months in July 2013 , reached $16.04 \mathrm{~g} /\left(\mathrm{m}^{2} \cdot \mathrm{d}\right)$. The seasonal variation of gross primary productivity was in the order of summer $>$ autumn $>$ spring $>$ winter. There was a significant spatial difference in primary productivity: in the horizontal distribution, the levels of primary productivity and respiratory capacity distribution similar to that the middle point of $\mathrm{H} 3$ obtain minimum, the $\mathrm{H} 4, \mathrm{H} 5$ of downstream at a higher level; in the vertical distribution, the maximum values of the gross primary productivity were obtained in the surface layer and $1 \mathrm{SD}$ layer, and along the water depth decreases gradually. The vertical distribution of respiratory capacity was different from gross primary productivity, the highest in 1 SD and 2 SD layer, and the value of each layer net primary productivity were smaller, and no obvious peak or valley value. This research showed that the coefficient of $P / R$ of phytoplankton of water column was less than 1 in Lake Taiping, while productivity of the highest layer ( surface layer) of coefficient of $P / R$ is greater than 1 . Correlation analysis showed that the temperature and deep lake were significantly positive correlation with
\end{abstract}

* 国家自然科学基金项目 $(31170441,31070419)$ 和上海师范大学原创与前瞻性预研项目 (DYL201304) 联合资助. 2016 - 01 - 07 收稿;2016-02-26 收修改稿.冯世敏( 1990 ), 男,硕士研究生;E-mail : uc_ok@ 126.com.

** 通信作者;E-mail:liudy@ shnu.edu.cn. 
the gross primary productivity of water column, and other environmental factors correlation were not obvious.

Keywords: Lake Taiping; primary productivity ; $P / R$ coefficient; chlorophyll-a; correlation analysis

湖泊是我国最重要的淡水资源之一. 由于开发利用湖泊流域资源的强度不断加大, 导致我国一些湖泊 出现了一系列的生态环境问题, 根据《2011 年中国环境状况公报》, 监测的 26 个国控重点湖泊 (水库) 中, $\mathrm{IV} \sim \mathrm{V}$ 类和劣 $\mathrm{V}$ 类水质的湖泊 (水库) 比例分别为 $50.0 \%$ 和 $7.7 \%$,因此,对湖泊的保护刻不容缓.

初级生产力是水生生态系统结构与功能的基础环节, 对研究水生生态系统及其环境特征具有重要意 $义^{[1]}$. 初级生产力则是指单位时间、单位空间内水域自养型生物吸收光能将无机物合成有机物的能力 ${ }^{[2]}$, 它 由浮游植物、着生藻类、水生维管束植物和自养细菌构成, 但浮游植物是主要原初生产者, 特别是在深水水 域, 水草和底生藻类微不足道, 浮游植物几乎是唯一的生产者 ${ }^{[3]}$. 初级生产力研究还可估算渔产潜力、评价 水体营养类型 ${ }^{[4-7]}$, 对评价水环境质量、指导渔业生产和生态保护具有重要价值, 同时对湖泊生态系统和湖 泊环境特征具有较强的指示作用 ${ }^{[8-9]}$.

太平湖 $\left(30^{\circ} 0^{\prime} \sim 30^{\circ} 32^{\prime} \mathrm{N}, 117^{\circ} 28^{\prime} \sim 118^{\circ} 21^{\prime} \mathrm{E}\right.$ ) 位于安徽黄山市黄山区境内, 于 1971 年建成蓄水, 流域面 积 $2800 \mathrm{~km}^{2}$, 库长约 $50 \mathrm{~km}$, 最大水深约 $70 \mathrm{~m}$, 平均水深约 $40 \mathrm{~m}$, 属于非典型峡谷型水库, 其上、中、下游均有 较大的敞水区, 其中最宽处约为 $4000 \mathrm{~m}$, 是安徽省最大的人工湖泊.

目前, 研究较多的以太平湖浮游藻类、底质沉积物和理化特征以及太平湖旅游为主 ${ }^{[10-13]}$, 但是关于太平 湖初级生产力的研究报道则较少, 太平湖初级生产力现状如何, 其动态变化过程以及影响因子所知更少. 鉴 于太平湖水域生态环境保护的重要性,从 2012 年 11 月至 2014 年 10 月对太平湖的初级生产力进行了为期 两年的调查研究, 旨在通过该项研究, 为太平湖流域生态环境保护以及水质良好型湖泊保护提供基础数据 和参考资料.

\section{1 材料与方法}

\section{1 采样点布设和采样时间}

2012 年 11 月- 2013 年 9 月期间每隔 2 个月对太平湖进行 1 次采样, 时间分别为 2012 年 11 月和 2013 年 1、3、5、7 和 9 月, 2013 年 9 月- 2014 年 10 月期间按每个季度采样 1 次, 分别为 2013 年 12 月和 2014 年 $4 、 7$ 和 10 月. 从上游至下游共设 5 个采样点, 分别为 $\mathrm{H} 1 、 \mathrm{H} 2 、 \mathrm{H} 3 、 \mathrm{H} 4 、 \mathrm{H} 5$ (图 1).

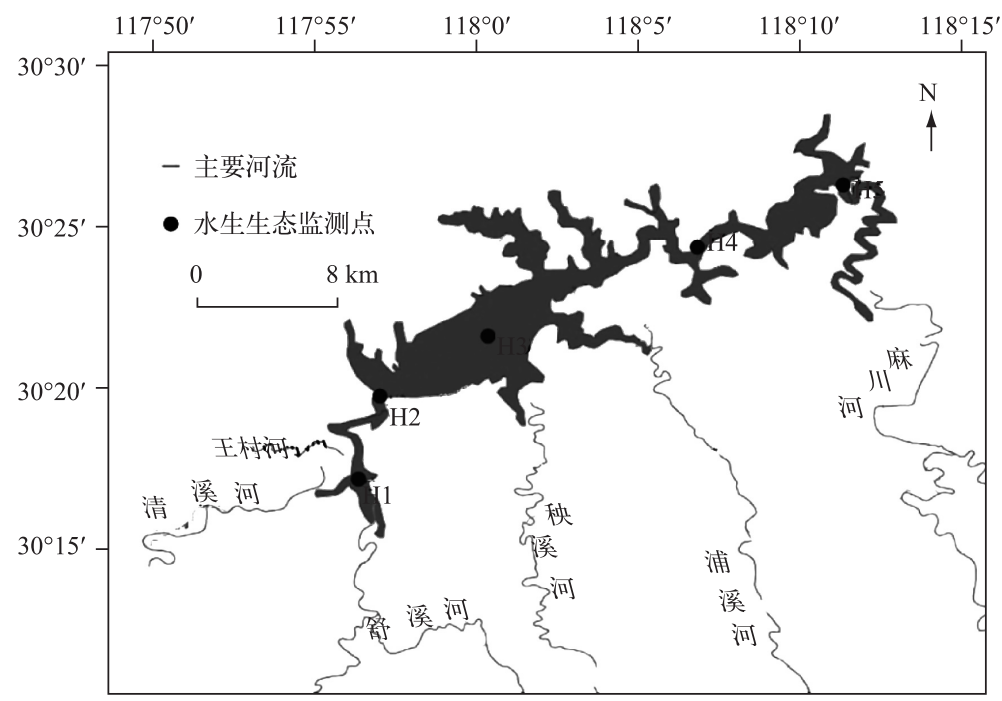

图 1 太平湖采样点布设

Fig.1 Distribution of sampling sites in Lake Taiping 


\section{2 样品采集与测定}

1.2.1 水质理化指标的测定 水质检测项目有透明度 $(\mathrm{SD})$ 、水深 $(\mathrm{D})$ 、溶解氧 ( DO)、水温 $(\mathrm{T})$ 和叶绿素 a (Chl.a). SD 采用萨氏盘测量;DO 浓度采用 HQ30D53 便携式溶解氧仪在现场测定; Chl.a 样品现场抽滤后闭 光保存带回实验室,依照国标水质叶绿素的测定分光光度法 (SL 88-2012) 测定 Chl.a 浓度.

1.2.2 初级生产力的采样与测定 采样依照中华人民共和国行业标准 SL 354-2006(水质初级生产力测定 法“黑白瓶”), 每天 12:00 之前完成. 黑白瓶分别采用 $150 \mathrm{ml}$ 棕色及无色磨口试剂瓶, 黑瓶外罩以黑布口袋 扎紧. 以水体透明度为分层依据, 分别将黑白瓶悬挂于表层 (水下 $0.5 \mathrm{~m}$ ) 处及 $1 、 2 、 3 、 4$ 倍透明度处, 即 $1 \mathrm{SD}$ 、 $2 \mathrm{SD} 、 3 \mathrm{SD} 、 4 \mathrm{SD}$ 处, 每次每层灌满 2 个白瓶、2 个黑瓶和 2 个原初瓶. 原初瓶于现场立即固定其瓶中的溶解 氧, 其它 4 瓶原位曝光 $24 \mathrm{~h}$, 取出后立即固定.

测定方法: 采用温克勒 (Winkler) 定氧法, 现场加人 $1 \mathrm{ml}$ 硫酸锰和 $2 \mathrm{ml}$ 碱性碘化钾, 分别固定黑白瓶中 的溶解氧, 封口摇匀, 带回实验室使用碘量法测定每个黑白瓶中的溶解氧 ${ }^{[14]}$. 实验结束后, 按下式分别计算 生产力和呼吸量:

$$
\begin{gathered}
P_{\mathrm{g}}=L B-D B \\
P_{\mathrm{n}}=L B-I B \\
R=I B-D B
\end{gathered}
$$

式中, $P_{\mathrm{g}}$ 为毛初级生产力; $P_{\mathrm{n}}$ 为净初级生产力; $R$ 为呼吸量; $I B$ 为原初瓶溶解氧量; $L B$ 为曝光结束白瓶溶解 氧量; $D B$ 为曝光结束黑瓶溶解氧量. 其中 $P_{\mathrm{g}} 、 P_{\mathrm{n}} 、 R$ 的单位为 $\mathrm{mg}\left(\mathrm{O}_{2}\right) /(\mathrm{L} \cdot \mathrm{d})$, 简写为 $\mathrm{mg} /(\mathrm{L} \cdot \mathrm{d})$.

水柱生产力是指 $1 \mathrm{~m}^{2}$ 垂直水柱的生产力. 根据各水层浮游植物 $P_{\mathrm{g}}$ 的大小, 采用算术平均值累计法计算, 计算得到水柱的毛生产力; 水柱呼吸量和水柱净生产力也用该法计算. 以水柱 $P_{\mathrm{g}}$ 为例,计算公式为:

$$
\text { 水柱 } P_{\mathrm{g}}=\sum_{i=1}^{n-1} \frac{P_{i}+P_{i+1}}{2} \cdot\left(D_{i+1}+D_{i}\right)
$$

式中, $P_{i}$ 为第 $i$ 层毛生产力, $D_{i}$ 为第 $i$ 层的深度, $n$ 为取样层数 $(1 \leqslant i \leqslant n-1)$.

\section{3 数据处理}

图表绘制在 Excel 2003 软件中进行,数据分析采用 SPSS 19.0 统计软件进行, 具体为 Pearson 相关性分 析和回归分析研究初级生产力与各理化因子之间的关系, 以及采用非参数统计检验中的配对样本 $T$ 检验和 克鲁斯凯一沃利斯方差分析进行差异性分析.

\section{2 结果与分析}

\section{1 透明度、水深、水温和溶解氧浓度}

水库是山沟或河流的狭口处建造拦河坝形成的人工湖泊,其水面宽阔、流速缓慢, 水的运动主要靠风力 和热对流. 湖水的透明度、温度、水深和溶解氧则是描述水库的基体指标, 也是初级生产力的基本环境因子. 太平湖透明度全年变化为 1.5 6.0 m, 不同采样点透明度差异较大, $\mathrm{H} 1$ 样点最低, H4、H5 样点最高; 而从 $\mathrm{H} 1$ 到 $\mathrm{H} 5$ 样点水深变化则为依次增大, 从季节来看夏秋季水深高于春冬季; H1 H5 样点水温变化范围分别为 7.4 27.9、8.22 7.9、8.8 28.1、9.6 28.1 和 $9.8 \sim 28.1{ }^{\circ} \mathrm{C}$, 各采样点水温变化范围基本一致; 溶解氧浓度则从 $\mathrm{H} 1$ 到 $\mathrm{H} 5$ 样点依次减小, 总的变化范围为 $5.3 \sim 11.3 \mathrm{mg} / \mathrm{L}$.

\section{2 初级生产力的时间分布}

太平湖浮游植物水柱日 $P_{\mathrm{g}}$ 在 0.94 9.22 $\mathrm{g} /\left(\mathrm{m}^{2} \cdot \mathrm{d}\right)$ 之间变化, 平均值为 $4.57 \mathrm{~g} /\left(\mathrm{m}^{2} \cdot \mathrm{d}\right)$, 最高值出现 在 2014 年 7 月,为 $9.22 \pm 4.22 \mathrm{~g} /\left(\mathrm{m}^{2} \cdot \mathrm{d}\right), 2012$ 年 11 月次之, 为 $8.36 \pm 3.58 \mathrm{~g} /\left(\mathrm{m}^{2} \cdot \mathrm{d}\right), 2014$ 年 4 月最低,为 $0.55 \pm 1.04 \mathrm{~g} /\left(\mathrm{m}^{2} \cdot \mathrm{d}\right)\left(\right.$ 图 2). 太平湖浮游植物 $P_{\mathrm{n}}$ 的最高值出现在 2014 年 4 月, 为 $2.39 \pm 0.79 \mathrm{~g} /\left(\mathrm{m}^{2} \cdot \mathrm{d}\right)$; 2014 年 10 月次之, 为 $1.99 \pm 1.04 \mathrm{~g} /\left(\mathrm{m}^{2} \cdot \mathrm{d}\right) ; 2013$ 年 7 月最低, 为 $-10.59 \pm 4.78 \mathrm{~g} /\left(\mathrm{m}^{2} \cdot \mathrm{d}\right)$. 水柱 $P \mathrm{~g}$ 与 $R$ 在 时间上变化趋势基本保持一致,在每年的 7 月左右出现峰值, 3、4 月出现谷值.

2013 年各采样时间点及 2014 年 7 月太平湖浮游植物日净生产力都出现负值, 特别在 7 月即夏季达到最 大. 虽其光照较强、水温较高, 浮游植物的光合作用较强, 但毛生产力较大的同时浮游动植物呼吸量也增加使 其大于毛生产力, 故其净生产力出现负值. 冬春季由于水温较低浮游植物光合作用较弱, 净生产力也出现了负值. 
表 1 太平湖透明度、水深、水温及溶解氧浓度

Tab.1 The transparency, water depth, temperature and dissolved oxygen of Lake Taiping

\begin{tabular}{|c|c|c|c|c|c|c|c|c|c|c|c|c|c|c|c|c|c|c|c|c|}
\hline \multirow{2}{*}{$\begin{array}{c}\text { 时间 } \\
\text { (年-月) }\end{array}$} & \multicolumn{4}{|c|}{ H1 } & \multicolumn{4}{|c|}{ H2 } & \multicolumn{4}{|c|}{ H3 } & \multicolumn{4}{|c|}{ H4 } & \multicolumn{4}{|c|}{ H5 } \\
\hline & $\begin{array}{c}\mathrm{SD} / \\
\mathrm{m}\end{array}$ & $\begin{array}{c}\mathrm{D} / \\
\mathrm{m}\end{array}$ & $\begin{array}{l}\mathrm{T} / \\
{ }^{\circ} \mathrm{C}\end{array}$ & $\begin{array}{c}\mathrm{DO} / \\
(\mathrm{mg} / \mathrm{L})\end{array}$ & $\begin{array}{c}\mathrm{SD} / \\
\mathrm{m}\end{array}$ & $\begin{array}{l}\mathrm{D} / \\
\mathrm{m}\end{array}$ & $\begin{array}{l}\mathrm{T} / \\
{ }^{\circ} \mathrm{C}\end{array}$ & $\begin{array}{c}\mathrm{DO} / \\
(\mathrm{mg} / \mathrm{L})\end{array}$ & $\begin{array}{c}\mathrm{SD} / \\
\mathrm{m}\end{array}$ & $\begin{array}{c}\mathrm{D} / \\
\mathrm{m}\end{array}$ & $\begin{array}{l}\mathrm{T} / \\
{ }^{\circ} \mathrm{C}\end{array}$ & $\begin{array}{c}\mathrm{DO} / \\
(\mathrm{mg} / \mathrm{L})\end{array}$ & $\begin{array}{c}\mathrm{SD} / \\
\mathrm{m}\end{array}$ & $\begin{array}{c}\mathrm{D} / \\
\mathrm{m}\end{array}$ & $\begin{array}{l}\mathrm{T} / \\
{ }^{\circ} \mathrm{C}\end{array}$ & $\begin{array}{c}\mathrm{DO} / \\
(\mathrm{mg} / \mathrm{L})\end{array}$ & $\begin{array}{c}\mathrm{SD} / \\
\mathrm{m}\end{array}$ & $\begin{array}{c}\mathrm{D} / \\
\mathrm{m}\end{array}$ & $\begin{array}{l}\mathrm{T} / \\
{ }^{\circ} \mathrm{C}\end{array}$ & $\begin{array}{c}\mathrm{DO} / \\
(\mathrm{mg} / \mathrm{L})\end{array}$ \\
\hline 2012-11 & 2.2 & 10.0 & 19.0 & 8.4 & 3.0 & 11.5 & 20.3 & 8.3 & 3.2 & 17.0 & 20.8 & 7.9 & 3.5 & 36.0 & 20.6 & 7.1 & 3.0 & 47.5 & 21.4 & 5.9 \\
\hline 2013-01 & 3.0 & 13.0 & 7.4 & 11.3 & 3.5 & 13.0 & 8.2 & 11.0 & 3.5 & 18.0 & 8.8 & 10.8 & 4.5 & 33.0 & 9.6 & 10.0 & 3.6 & 45.0 & 9.8 & 9.8 \\
\hline 2013-03 & 2.0 & 16.5 & 13.6 & 11.1 & 5.0 & 18.0 & 11.8 & 10.6 & 2.0 & 19.5 & 11.9 & 11.3 & 3.0 & 34.5 & 12.5 & 10.6 & 4.5 & 51.0 & 11.6 & 10.5 \\
\hline 2013-05 & 2.5 & 16.5 & 26.8 & 10.7 & 3.5 & 15.0 & 27.2 & 9.1 & 4.5 & 20.0 & 25.8 & 8.7 & 5.0 & 42.0 & 24.2 & 9.3 & 3.0 & 51.5 & 24.1 & 9.5 \\
\hline 2013-07 & 2.0 & 18.5 & 27.4 & 8.3 & 2.0 & 19.0 & 27.1 & 8.0 & 2.0 & 22.0 & 27.4 & 7.9 & 3.0 & 36.5 & 28.1 & 7.8 & 4.0 & 52.5 & 27.0 & 8.0 \\
\hline 2013-09 & 1.5 & 12.5 & 27.9 & 7.4 & 1.5 & 14.0 & 27.9 & 7.5 & 2.0 & 16.0 & 28.1 & 7.2 & 3.0 & 26.0 & 28.0 & 6.5 & 3.0 & 45.5 & 28.0 & 6.1 \\
\hline 2013-12 & 2.0 & 12.5 & 7.6 & I & 2.0 & 12.0 & 9.8 & 10.0 & 3.5 & 14.0 & 10.6 & 10.2 & 3.0 & 21.0 & 12.0 & / & 3.5 & 43.5 & 12.5 & 7.8 \\
\hline 2014-04 & 2.0 & 13.0 & 17.4 & 8.3 & 3.5 & 15.0 & 11.8 & 8.4 & 3.5 & 17.0 & 13.9 & 9.8 & 6.0 & 16.0 & 13.3 & 9.3 & 6.0 & 47.5 & 12.6 & 9.3 \\
\hline 2014-07 & 2.0 & 19.5 & 27.1 & 8.6 & 3.0 & 19.0 & 28.1 & 8.6 & 3.0 & 24.5 & 27.8 & 8.0 & 5.0 & 29.0 & 27.2 & 8.0 & 4.0 & 53.0 & 28.1 & 8.1 \\
\hline 2014-10 & 2.0 & 18.0 & 24.4 & 5.6 & 2.0 & 18.0 & 24.4 & 5.4 & 2.0 & 23.0 & 24.4 & 6.4 & 2.0 & 28.0 & 24.3 & 6.6 & 3.0 & 52.0 & 24.0 & 5.3 \\
\hline
\end{tabular}

“/”代表数据缺失.

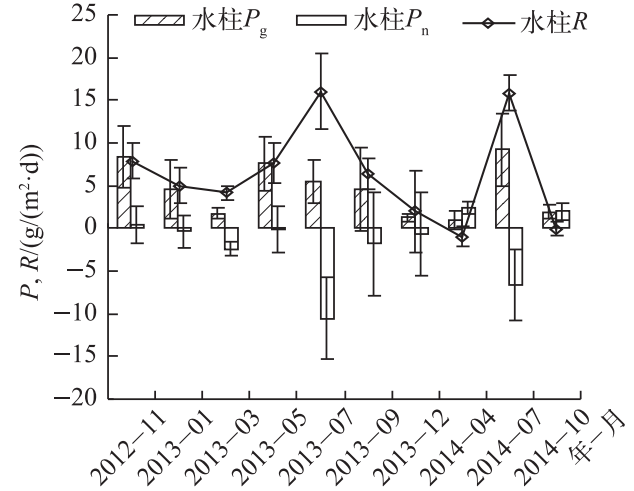

图 2 太平湖初级生产力和呼吸量变化

Fig. 2 Changes of primary productivity and respiratory capacity of Lake Taiping
凶春季 口夏季 日秋季 曰冬季

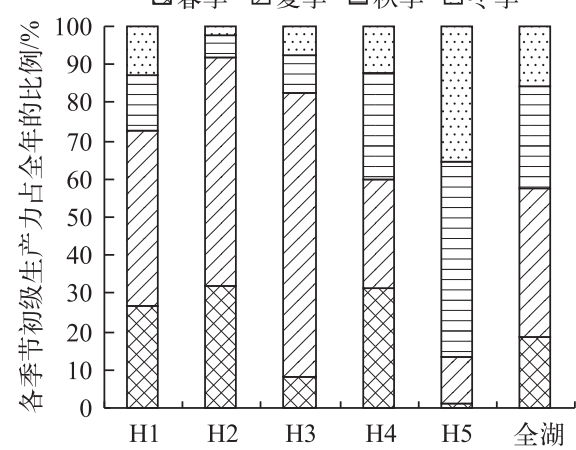

图 3 各采样点不同季节初级生产力占全年比例

Fig. 3 The seasonal distribution of primary productivity at different sampling sites

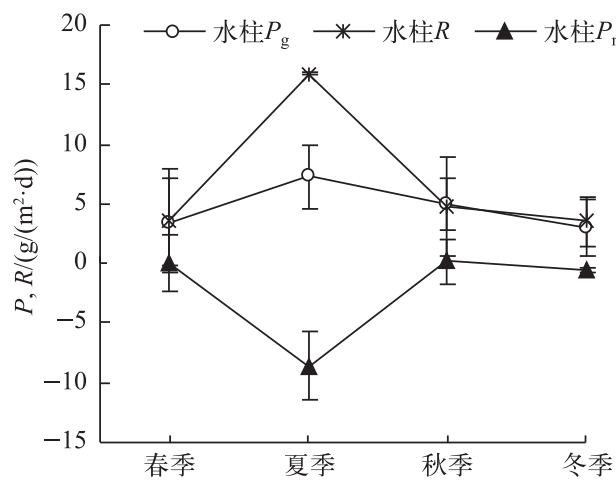

图 4 水柱日初级生产力和呼吸量的季节变化

Fig.4 Seasonal variation of primary productivity and respiratory capacity in water column
太平湖初级生产力的季节差异较明显, 全湖春季、夏 季、秋季和冬季 4 个季节初级生产力占全年的比例分别 为 $18 \% 、 39 \% 、 27 \%$ 和 $16 \%$, 配对样本 $\mathrm{T}$ 检验显示, 不同季 节的初级生产力有显著性差异, 夏季显著高于秋季 $(P=$ $0.012<0.05)$ 和冬季 $(P=0.049<0.05)$, 秋季显著高于冬季 $(P=0.004<0.05)$, 而春季与夏季、冬季无显著性差异 $(P>$ 0.05 ) (图 3、4).

将全湖按季节进行分析 (图 4), 不同季节初级生产力 水平有明显差异, 春季、夏季、秋季和冬季 4 个季节初级生 产力的平均值分别为 $3.29 \pm 3.76 、 7.33 \pm 2.67 、 4.97 \pm 2.10$ 和 $2.95 \pm 2.36 \mathrm{~g} /\left(\mathrm{m}^{2} \cdot \mathrm{d}\right)$, 表现为夏季 $>$ 秋季 $>$ 春季 $>$ 冬季的特 征. 太平湖不同季节水柱 $P_{\mathrm{g}}$ 与水柱 $R$ 比较, 则表现为夏季 $P_{\mathrm{g}}>R$, 春、秋、冬季 $P_{\mathrm{g}}<R$. 


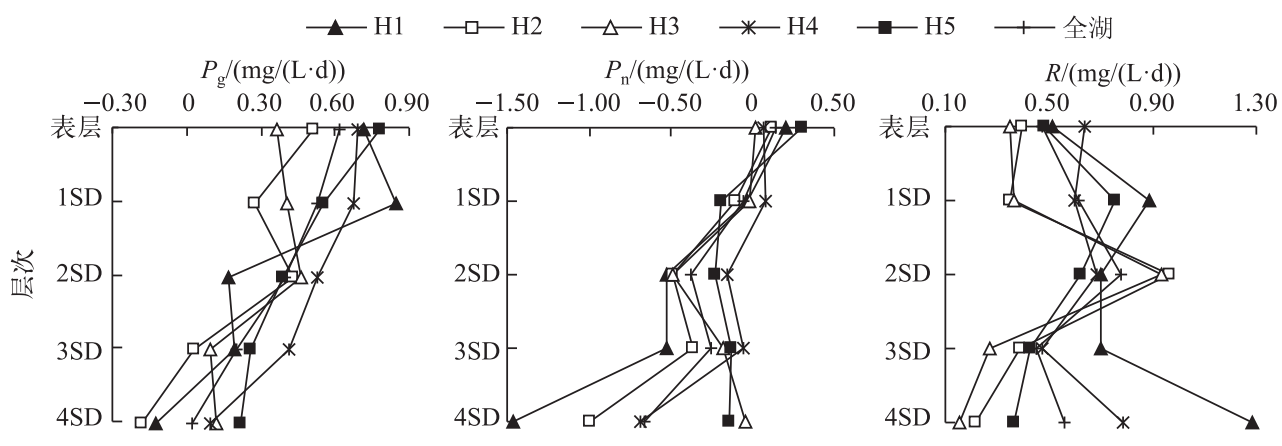

图 5 不同样点初级生产力与呼吸量的垂直分布

Fig.5 The vertical distribution of primary productivity and respiratory capacity in different sampling sites

\section{3 不同样点和不同季节初级生产力的垂直分布}

总体来看, 太平湖 $P_{\mathrm{g}}$ 和 $P_{\mathrm{n}}$ 最高值均出现在表层和

$1 \mathrm{SD}$ 层, 分别达 $0.85 \pm 0.37$ 和 $0.14 \pm 0.11 \mathrm{mg} /(\mathrm{L} \cdot \mathrm{d})$, 表层、 $1 \mathrm{SD} 、 2 \mathrm{SD} 、 3 \mathrm{SD}$ 和 $4 \mathrm{SD}$ 层 $P_{\mathrm{g}}$ 占全湖的百分比分别 为 35\%、30\%、22\%、11\% 和 2\% (图 5), 并随水深逐渐降低, 这与卢子园等 ${ }^{[15]}$ 对淀山湖的研究相一致. 将各水 层的初级生产力测定值进行算术平均, 再进行拟合, 分别得到 $P_{\mathrm{g}}$ 和 $P_{\mathrm{n}}$ 沿物理层次 $\mathrm{SD}$ 分布的回归方程: $P_{\mathrm{g}}=$ 0.575-0.085 $S D(P<0.01), P_{\mathrm{n}}=0.069-0.129 S D(P<0.01)$. 通过对 $P_{\mathrm{n}}$ 的回归方程分析得出补偿深度, 即 $P_{\mathrm{n}}=$ 0 的水层深度, 对于太平湖而言补偿深度为 0.5 倍透明度. 从上游 $\mathrm{H} 1$ 样点到下游 $\mathrm{H} 5$ 样点各层 $P_{\mathrm{g}}$ 呈先升后 降再升再降的变化趋势, 这与浮游动植物生物量变化趋势相一致 ${ }^{[16]}$.

各层不同季节 $P_{\mathrm{g}}$ 比较发现, 表层和 $1 \mathrm{SD}$ 层表现为夏季>秋季>春季>冬季, 与全湖季节变化相同, 在 $2 \mathrm{SD}$ 层表现为夏季 $>$ 春季 $>$ 秋季 $>$ 冬季,到 3SD 层秋季最大,其它季节无明显变化 (图 6), 这可能与湖下各层水环 境差异有关, 张琪等 ${ }^{[24]}$ 等对香溪河初级生产力影响因素研究表明,适宜的水环境因子是春、夏季初级生产力 高的主要原因. 总的来看,春、夏、秋季最大 $P_{\mathrm{g}}$ 一般出现在表层,这可能是由于随着深度的增加,光强减弱 $P_{\mathrm{g}}$ 明显降低, 到冬季时温度低光强也较弱, 故其各层 $P_{\mathrm{g}}$ 都很低且各层间无明显差异, 这与张运林等 ${ }^{[17]}$ 研究太 湖梅梁湾的研究结果相同. 从全年来看, $P_{\mathrm{g}}$ 表现为 $1 \mathrm{SD}$ 层 $>2 \mathrm{SD}$ 层 $>3 \mathrm{SD}$ 层 $>4 \mathrm{SD}$ 层, 再次证明表层与 $1 \mathrm{SD}$ 层 是太平湖生产力的主要贡献者. 各季节 $R$ 表现为夏季>秋季>春季>冬季, 各层之间变化不大, 夏季、秋季、春 季和冬季 $R$ 变化范围分别为 $0.85 \sim 1.85 、 0.23 \sim 0.56 、-0.03 \sim 0.51$ 和 $-0.09 \sim 0.70 \mathrm{mg} /(\mathrm{L} \cdot \mathrm{d})$.

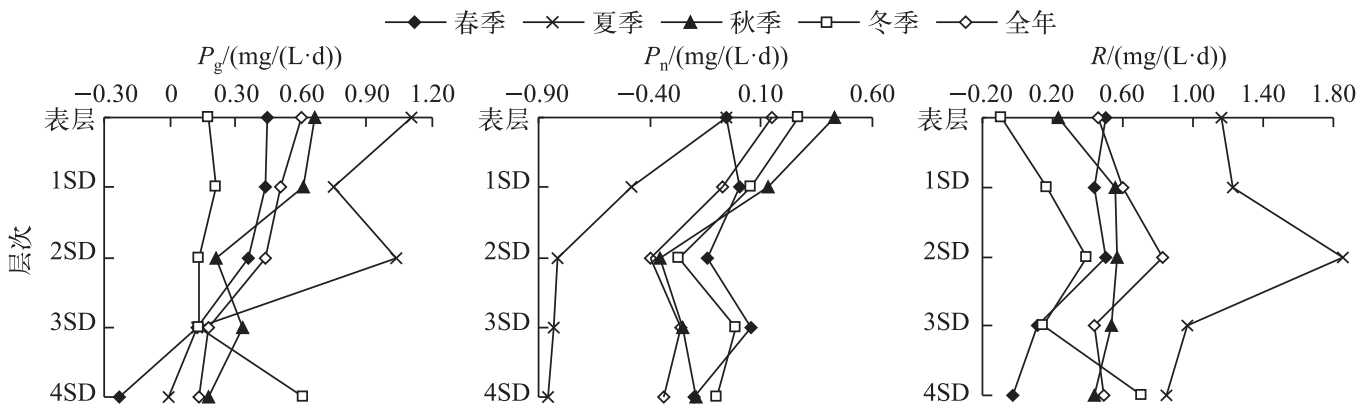

图 6 不同季节初级生产力与呼吸量的垂直分布

Fig. 6 The vertical distribution of primary productivity and respiratory capacity in different seasons

\section{4 初级生产力水平分布}

水柱 $P_{\mathrm{g}}$ 与水柱 $R$ 都在湖心 $\mathrm{H} 3$ 样点处最小, 下游 $\mathrm{H} 4 、 \mathrm{H} 5$ 样点无论是 $P_{\mathrm{g}}$ 与 $R$ 都处于较高水平, 整体而 言, $P_{\mathrm{g}}>R$ (图 7), 水柱 $P_{\mathrm{n}}$ 整体处于较低水平. 组间差异分析表明, 采样点组间 $P_{\mathrm{g}}$ 存在显著差异性 $(P<0.05)$, 其中 $\mathrm{H} 1 、 \mathrm{H} 2$ 样点均与 $\mathrm{H} 3$ 样点呈显著差异, $\mathrm{H} 1$ 与 $\mathrm{H} 2$ 样点呈显著差异, 说明 $\mathrm{H} 1$ 和 $\mathrm{H} 2$ 样点的生产力处于同 


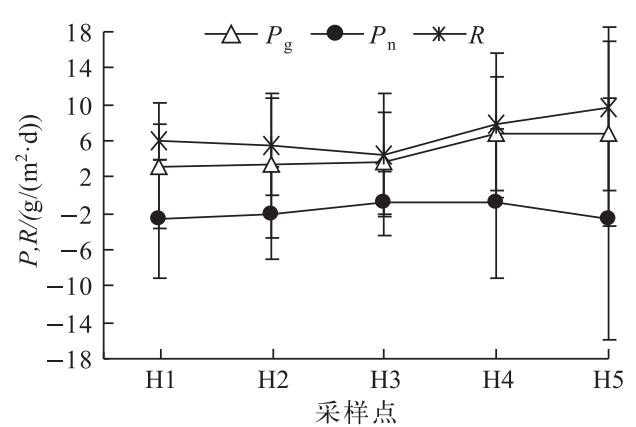

图 7 太平湖各采样点水柱 $P_{\mathrm{g}}, P_{\mathrm{n}}$ 和 $R$ 的水平变化

Fig.7 The horizontal distribution of $P_{\mathrm{g}}, P_{\mathrm{n}}$ and $R$ in different sampling sites of Lake Taiping

表 2 浮游植物的 $P / R$ 系数统计值

Tab.2 Descriptive statistics of $P / R$ coefficients of phytoplankton

\begin{tabular}{lccccc}
\hline 指标 & $N$ & \multicolumn{5}{c}{ 最小值 } & 最大值 & 平均值 & 标准差 \\
\hline 表层 $P_{\mathrm{g}} / R$ & 46 & -1.19 & 4.86 & 1.52 & 2.78 \\
水柱 $P_{\mathrm{g}} / R$ & 10 & 0.34 & 1.06 & 0.71 & 1.62 \\
\hline
\end{tabular}

一水平, 其余各点差异性不明显.

\section{5 太平湖的 $P / R$ 系数}

$P / R$ 系数可以反映某一种群或群落生物的代谢水 平, 又称为群落代谢率, 对于特定植物种群, $P / R$ 系数可 以反映种群对环境的适应情况, 其关系大致为: $P / R>1$, 种群增长, 生态系统不稳定; $P / R=1$, 种群不增不减, 生态 系统稳定; $P / R<1$, 种群减少, 生态系统不稳定.

一般, $P / R$ 系数的 $P$ 值通常用 $P_{\mathrm{g}}$ 表示, 本文 $P / R$ 系 数也用 $P_{g}$ 进行计算. 最高水层和水柱的 $P / R$ 系数均值都 小于 1 , 说明太平湖浮游植物群落种群减少, 生态系统不 稳定,表层 $P / R$ 系数与水柱 $P / R$ 系数见表 2 .

太平湖属于藻型湖泊, 生产量主要来自于藻类的光 合作用; 呼吸量除包括浮游植物本身耗氧外, 还包括细 菌、浮游动物等的耗氧量. 生产量与呼吸量的相对值 $P / R\left(P\right.$ 代表 $P_{\mathrm{g}}, R$ 代表呼吸量) 具有重要的生态学意义, 是反映水生生态系统生产力结构的重要指标. 通常在湖 泊系统中, $P / R>1$ 表明生态系统以自养过程为主导, 而 $P / R<1$ 则表明以异养生产为主. 一般在贫营养和中营养 湖泊中 $P / R<1$, 在富营养湖泊中 $P / R>1^{[19]}$. 太平湖 $P / R$ 平均值为 0.71 , 即生产量小于呼吸量, 说明太平湖整体呈 现异养型特征. $P / R$ 值的垂向分布特点与 $P_{\mathrm{g}}$ 相似; 且表 层的 $P / R$ 大于 1 , 为自养状态, $1 \mathrm{SD} 、 2 \mathrm{SD}$ 和 $3 \mathrm{SD}$ 层的 $P / R$ 值小于 1 , 异养作用强烈, 这也再次证明了表层水 体是太平湖主要的生产层.

\section{6 初级生产力与理化因子的相关性}

通过 SPSS 19.0 软件建立各采样期间各水层 $P_{\mathrm{g}} 、 R 、 P_{\mathrm{n}}$ 与各环境因子的 Pearson 相关分析 (表 3), 结果表 明: $P_{\mathrm{g}}$ 与水温呈极显著正相关 $(P<0.01)$, 且与水深也呈显著相关 $(P<0.05) ; R$ 与水温呈显著正相关, $P_{\mathrm{n}}$ 则与 水温呈显著负相关.

\section{表 $3 P_{\mathrm{g}} 、 R$ 和 $P_{\mathrm{n}}$ 与环境各因子的相关性矩阵}

Tab.3 The correlation matrix of $P_{\mathrm{g}}, R$ and $P_{\mathrm{n}}$ and each environmental factor

\begin{tabular}{|c|c|c|c|c|c|c|c|}
\hline & $P_{\mathrm{g}}$ & $R$ & $P_{\mathrm{n}}$ & 水温 & 溶解氧 & 透明度 & 水深 \\
\hline$P_{\mathrm{g}}$ & 1 & & & & & & \\
\hline$R$ & $0.476^{* *}$ & 1 & & & & & \\
\hline$P_{\mathrm{n}}$ & $0.469^{* *}$ & $-0.547^{* *}$ & 1 & & & & \\
\hline 温度 & $0.223^{* *}$ & $0.431^{* *}$ & $-0.221 * *$ & 1 & & & \\
\hline 溶解氧 & -0.103 & -0.052 & -0.045 & $-0.634^{* * *}$ & 1 & & \\
\hline 透明度 & -0.032 & -0.085 & 0.131 & 0.011 & $-0.188^{* *}$ & 1 & \\
\hline 水深 & $0.148^{*}$ & 0.001 & 0.131 & 0.075 & $-0.188^{* *}$ & $0.187^{\text {*** }}$ & 1 \\
\hline
\end{tabular}

** 表示显著性水平为 $0.01, *$ 表示显著性水平为 0.05 .

\section{3 讨论}

\section{1 环境因子对初级生产力的影响}

水温、DO、透明度、水深是与初级生产力密切相关的环境因子, 研究其对初级生产力相互关系有助于对 太平湖生态系统结构与功能的认识. 
浮游植物是太平湖主要的初级生产者, 而浮游植物的多少与其光合作用的强弱有关, 光合作用的强弱 则与太平湖水体透明度有关, 因此水体透明度也是浮游植物初级生产力的影响因素之一. 浮游植物进行光 合作用的同时向水体释放出氧气, 从而溶解氧浓度的高低能表征浮游植物生长和增殖情况, 因此水体中溶 解氧浓度也与浮游植物初级生产有关. 水温一方面可以通过控制光合作用的酶促进反应或呼吸作用强度, 直接影响浮游植物生产过程, 也可通过控制水体中的各类营养物的溶解度、离解度或分解率等理化过程, 间 接影响浮游植物的生产力. $P_{\mathrm{g}}$ 与水温呈极显著正相关, 即在夏季最高, 这与赵文等 ${ }^{[19]}$ 对盐碱池塘浮游植物初 级生产力的研究相同, $P_{\mathrm{g}}$ 与水深呈显著正相关; $R 、 P_{\mathrm{n}}$ 与水温分别呈极显著正相关 (图 8). 对各理化因子进行 多元逐步回归分析发现, 在整个调查期间太平湖毛初级生产力主要限制因素是水温与水深,其回归方程为: $P_{\mathrm{g}}=-0.177+0.02 T+0.006 \mathrm{D}$. 对于不同的水体, 影响浮游植物初级生产力的主要因素也不尽相同, 张运林 等 ${ }^{[20]}$ 研究表明, 太湖初级生产力主要受温度和光强的影响. 熊倩等 ${ }^{[21]}$ 对三峡水库浮游植物初级生产力季节 变化研究表明,光可获得性可能是其重要的限制因素.

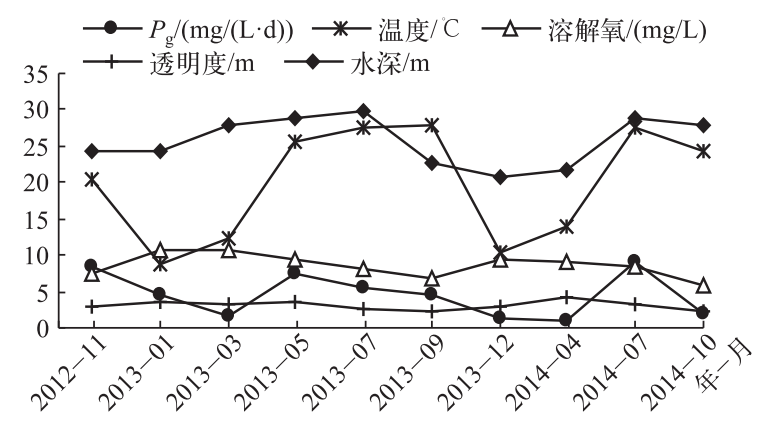

图 8 初级生产力与环境因子的关系

Fig. 8 Relationship between primary productivity and environmental factors

太平湖浮游植物初级生产力季节变化表现为夏季最高, 秋季次之, 春冬季较低 (图 8), 研究表明水温为 其主要的影响因子, 夏、秋季水温较高, 达到一个适宜环境, 而春冬季水温较低, 光强也较弱, 浮游植物光合 作用受到抑制, 因此春冬季初级生产力低于夏秋季. 不同研究区域其初级生产力的季节变化亦有明显差异, 如淀山湖初级生产力表现为夏季最高, 冬季次之, 春秋季较低, 这可能与淀山湖浮游植物群落结构和优势种 的更替有关 ${ }^{[3]}$, 而朱爱民等 ${ }^{[8]}$ 对湖北浮河桥水库的研究表明, 浮河桥水库初级生产力季节分布规律为秋季 最高,夏季次之,春冬季较低,这与其浮游植物叶绿素 $\mathrm{a}$ 浓度和生物量的季节变化相一致.

同一季节的不同采样点初级生产力也不尽相同, 这可能与各采样点的水质水文差异有关. 太平湖周边 主要共有五大子流域, 自东向西依次为麻川河流域、浦溪河流域、秧溪河流域、舒溪河流域和清溪河流域. 各 流域的土地利用结构对河流水质的影响较显著, 从而影响太平湖上游至下游的水质情况. 陆君等 ${ }^{[22]}$ 对太平 湖流域研究表明水质污染指标与耕地、建设用地、园地呈正相关, 与林草地呈负相关. 刘佩佩等 ${ }^{[23]}$ 在湖泊沼 泽化与水生植物初级生产力研究中讲到, 水文要素的变化也会导致水生态系统中食物网和种间关系的相应 改变, 从而导致各采样点浮游植物初级生产力存在显著差异.

\section{2 表层初级生产力与表层叶绿素 $\mathrm{a}$ 浓度的相关分析}

叶绿素 $\mathrm{a}$ 是重要的光合色素, 是浮游植物将光能转化为化学能的重要载体. 一般来说, 水体叶绿素 a 浓 度的分布与环境因子, 如温度、盐度、光照、营养盐浓度分布等密切相关, 也直接反映了初级生产力的分布. 理论上水体叶绿素 $\mathrm{a}$ 浓度的变化与水柱初级生产力之间应该存在明确的对应关系, 但实际研究中由于研究 的对象及时间不同, 结果差异很大. 许多研究表明叶绿素 $\mathrm{a}$ 浓度与初级生产力有显著的相关关系 ${ }^{[17,24]}$, 也有 许多研究得出初级生产力与叶绿素 a 浓度无显著相关性的结论 ${ }^{[25-26]}$, 同一研究, 对于不同的位点或采样时 间, 甚至得出相反的结论 ${ }^{[27]}$. 由于浮游动物的摄食作用, 叶绿素 $\mathrm{a}$ 浓度只能反映水体中浮游植物的现存量, 不能完全反映水体中初级生产力水平, 蔡琳琳等 ${ }^{[28]}$ 对太湖的研究证明了浮游动物对初级生产力的影响.

除 2013 年 9 月、2014 年 10 月叶绿素 $\mathrm{a}$ 浓度较高外, 其余月份表层叶绿素 $\mathrm{a}$ 浓度变化较平稳. 对其进行 
相关性分析,结果表明,本次研究期间太平湖水库的表层初级生产力与表层叶绿素 $\mathrm{a}$ 浓度在 $P<0.05$ 水平上 未呈现显著的相关性 (相关系数为 0.021 ), 这与孙松等 ${ }^{[25]}$ 对胶州湾初级生产力周年变化研究类似. 从时间 分布来看, 表层毛生产力在 7 月份左右出现峰值, $3 、 4$ 月份出现谷值这与浮游动物丰度变化相同 ${ }^{[16]}$, 而表层 浮游植物叶绿素 a 浓度的时间变化要推迟 2 个月左右出现峰谷值 (图 9), 这可能与不同营养水平和环境下 藻类种类及藻类对光的适应和利用效率以及浮游动物、贝类等的摄食有关.

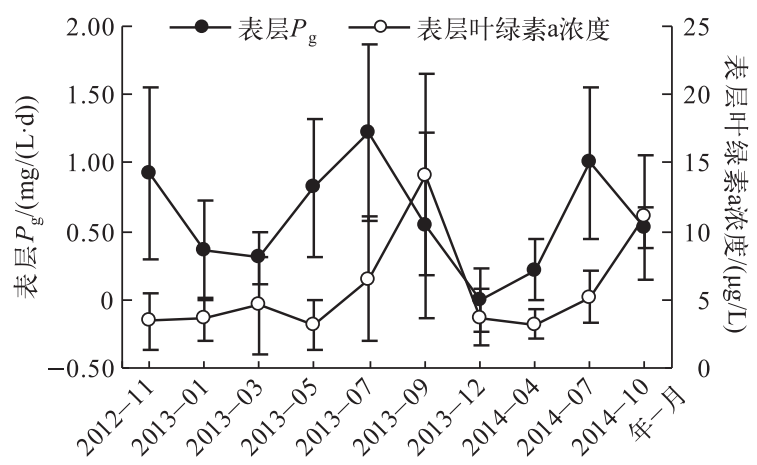

图 9 表层初级生产力与叶绿素 $\mathrm{a}$ 浓度的关系

Fig.9 Relationship between primary productivity and chlorophyll-a concentration in surface layer

\section{4 结论}

调查期间, 太平湖水库水柱 $P_{\mathrm{g}} 、 P_{\mathrm{n}}$ 和 $R$ 的总平均值分别为 $4.54 \pm 6.72 、-1.82 \pm 7.77$ 和 $6.50 \pm 7.62 \mathrm{~g} /\left(\mathrm{m}^{2} \cdot \mathrm{d}\right)$. 水柱 $P_{\mathrm{g}}$ 存在显著季节变化, 表现为夏季>秋季>春季>冬季, 主要受水温、DO、透明度、水深的影响,其中水温 和水深对其影响较大. 而太平湖水库初级生产力具有显著的空间差异, 湖心 $\mathrm{H} 3$ 样点处最小,下游的 H4、H5 样点处于较高的水平. 垂直分布显示, $P_{\mathrm{g}}$ 主要贡献在表层和 $1 \mathrm{SD}$ 层,并沿水深逐渐降低, $R$ 的垂直分布与 $P_{\mathrm{g}}$ 不同, 最高值出现在 $1 \mathrm{SD}$ 和 $2 \mathrm{SD}$ 层, 各层净生产力的值均较小, 无明显峰值或谷值. 太平湖水库水柱的 $P / R$ 系数小于 1 ,表现为异养型,但最高生产力层 (表层) 的 $P / R$ 系数则大于 1 ,表现为自养型.

\section{5 参考文献}

[ 1 ] Odum HT. Primary production in flowing waters. Limnology and Oceonography, 1956, 1(2) : 102-117. DOI : 10.4319/10. 1956.1.2.0102.

[ 2 ] Peng Gang, Li Xiaoxuan, Hao Chen et al. The determination of the primary production of phytoplankton in summer in Gehu lake. Fisheries Economy Research, 2007, (1) : 46-48(in Chinese). [ 彭刚, 李潇轩, 郝忱等. 滆湖夏季浮游植物初 级生产力测定. 渔业经济研究, 2007, (1) : 46-48.]

[ 3 ] Wang Yipin, Zhang Weiyan, Xu Chunyan et al. Phytoplankton productivity and its influencing factors in Dianshan Lake. Environmental Science, 2011, 32(5) : 1249-1256(in Chinese with English abstract). [汪益嫔, 张维砚, 徐春燕等. 淀 山湖浮游植物初级生产力及其影响因子. 环境科学, 2011, 32(5): 1249-1256. ]

[ 4 ] Kennedy JT, Whalen SC. Seasonality and controls of phytoplankton productivity in the middle Cape Fear River, USA. Hydrobiologia, 2008, 598(1) : 203-217. DOI : 10.1007/s10750-007-9151-9.

[ 5 ] Boulion VV. Contribution of major groups of autotrophic organisms to primary production of water bodies. Water Resources, 2004, 31(1) : 92-102. DOI: 10.1023/B: WARE.0000013579.89883.55.

[6] Chen Jing. Research on primary productivity and fishery potential of Guocun Reservoir. Journal of Anhui Agricultural Sciences, 2011, 39(7) : 4032-4033(in Chinese with English abstract). [ 陈静. 郭村水库初级生产力及渔产潜力研究. 安 徽农业科学, 2011, 39(7): 4032-4033.]

[ 7 ] Wei Zhong, Bao Chuanhe, Ding Shuquan et al. Assessment and analysis of primary production and fish productivity in Wanfo Lake. Journal of Anhui Agricultural University, 2012, 39(6) : 871-874( in Chinese with English abstract). [ 韦众, 
鲍传和, 丁淑荃等. 万佛湖初级生产力和鱼产力的评估与分析. 安徽农业大学学报, 2012, 39(6): 871-874.]

[ 8 ] Zhu Aimin, Liu Jiashou, Hu Chuanlin et al. Primary production of phytoplankton and its management in Fuqiaohe Reservoir, Hubei Province. J Lake Sci, 2007, 19(3) : 340-344(in Chinese with English abstract). DOI : 10.18307/2007.0317. [ 朱爱民, 刘家寿, 胡传林等. 湖北浮桥河水库浮游植物初级生产力及其管理. 湖泊科学, 2007, 19(3): 340-344.]

[ 9 ] Li Zhu, Guo Weijie, Cheng Shuiping et al. The spatial and temporal distribution of chlorophyll-a and its correlation with environmental factors Nanfeihe River. Acta Hydrobiologica Sinica, 2014, 38(2) : 342-350 (in Chinese with English abstract). DOI: 10.7541/2014.49. [李 柱, 郭伟杰, 成水平等. 南淝河叶绿素 a 时空分布特征及环境因子影响分析. 水 生生物学报, 2014, 38(2) : 342-350.]

[10] Kuang Qijun, Xia Yicheng. Community dynamics of algae and limiting nutrient in Taipinghu Reservoir. J Lake Sci, 1995, 7(3) : 235-238 (in Chinese with English abstract). DOI: 10.18307/1995.0305. [况琪军, 夏宜琤. 太平湖水库藻类演 替与营养侦别研究. 湖泊科学, 1995, 7(3): 235-239.]

[11] Zhang Shuiyuan, Liu Quxia, Hua Li. Physico-chemical characteristics of Taiping Reservoir. Acta Hydrobiologica Sinica, 2000, 24(5) : 530-536( in Chinese with English abstract). [ 张水元, 刘倠霞, 华俐. 太平湖水库水质的理化特征. 水 生生物学报, 2000, 24(5): 530-536.]

[12] Liu Yafeng, Qian Liping, Huang Honghui et al. Distribution patterns of heavy metals in surface sediments and environmental quality assessment on the Taipinghu basin of Anhui Province. Journal of Fudan Univerisity: Natural Science, 2015,54 (2) : 220-227 (in Chinese with English abstract). [刘亚风, 钱丽萍, 黄洪辉等. 安徽太平湖流域底质沉积物多种重 金属和砷的分布特征及环境评价. 复旦学报: 自然科学版, 2015, 54(2): 220-227.]

[13] Lu Lin, Tian Na, Yu Hu et al. The evolution process and mechanism of Lake Taiping in Anhui province. Journal of Natural Resources, 2015, 30(4) : 604-615(in Chinese with English abstract). DOI: 10.11849/zrzyxb.2015.04.007. [ 陆林, 天娜, 虞虎等. 安徽太平湖旅游地演化过程及机制. 自然资源学报, 2015, 30(4): 604-615.]

[14] State Environmental Protection Administration “Water and wastewater monitor the analytical method” Editorial Board. Water and wastewater monitor the analytical method(3rd ed). Beijing: China Environmental Science Press, 1989: 246-248. [ 国家环境保护局. 水和废水监测分析方法(第三版). 北京: 中国环境科学出版社, 1989: 246-248.]

[15] Lu Ziyuan, Wang Liqing, Ji Gaohua et al. Control of Dianshan Lake eutrophication based on the primary productivity of silver carp and bighead carp. Journal of Ecology, 2010, 29(7): 1365-1370 (in Chinese with English abstract). [ 卢子园， 王丽卿, 季高华等. 淀山湖基于初级生产力的鲢鳙富营养化控制. 生态学杂志, 2010, 29(7) : 1365-1370.]

[16] Xiong Lian, Liu Dongyan, Wang Junli et al. Phytoplankton community structure in Lake Taiping of Auhui Province. J Lake $S c i, 2016,28(5)$ : 1066-1077. DOI: 10.18307/2016.0517. [ 熊莲, 刘冬燕, 王俊莉等. 安徽太平湖浮游植物群落结 构. 湖泊科学, 2016, 28(5): 1066-1077.]

[17] Zhang Yunlin, Qin Boqiang, Chen Weimin et al. Phytoplankton primary production in spring Meiliang, Lake Taihu. J Lake Sci , 2005, 17(1) : 81-86(in Chinese with English abstract). DOI:10.18307/2005.0113. [张运林, 秦伯强, 陈伟 民等. 太湖梅梁湾春季浮游植物初级生产力. 湖泊科学, 2005, 17(1) : 81-86.]

[18] Delgiorgio PA, Peters RH. The balance between phytoplankton production and plankton respiration in lakes. Canadian Journal of Fisheries and Aquatic Sciences, 1993, 50(2) : 282-289.

[19] Zhao Wen, Dong Shuanglin, Li Deshang et al. The primary productivity of phytoplankton in Saline-alkaline ponds. Acta Hydrobiologica Sinica, 2003, 27(1): 47-54(in Chinese with English abstract). [ 赵文, 董双林, 李德尚等. 盐碱池塘 浮游植物初级生产力的研究. 水生生物学报, 2003, 27(1): 47-54.]

[20] Zhang Yunlin, Qin Boqiang, Chen Weimin et al. Experimental study on under water light intensity and primary productivity caused by variation of total suspended matter. Advances in Water Science, 2004, 15(5) : 615-620( in Chinese with English abstract). [张运林, 秦伯强, 陈伟民等. 悬浮物浓度对水下光照和初级生产力的影响. 水科学进展, 2004,15 (5) : 615-620.]

[21] Xiong Qian, Huang Licheng, Ye Shaowen et al. The seasonal variations and spatial distribution of the primary productivities of phytoplankton in the three gorges reservoir. Acta Hydrobiologica Sinica, 2015, 39(5) : 853-860 (in Chinese with English abstract). DOI : 10.7541/2015.113. [ 熊倩, 黄立成, 叶少文等. 三峡水库浮游植物初级生产力的季节变化与 空间分布. 水生生物学报, 2015, 39(5): 853-858.]

[22] Lu Jun, Liu Yafeng, Huang Honghui et al. Correlation analysis between land use structure and water quality of the Lake 
Taiping watershed in Huangshan. Journal of Fudan University (Natural Science), 2014, (6) : 731-736,746(in Chinese with English abstract). [ 陆君, 刘亚风, 黄洪辉等. 黄山市太平湖流域土地利用结构与河流水质相关性分析. 复旦 学报(自然科学版), 2014,(6): 731-736,746.]

[23] Liu Peipei, Bai Junhong, Zhao Qinqin et al. A review on terrestrialization and primary productivity of aquatic vegetations in lake ecosystems. Wetland Science, 2013, 11(3) : 392-397 (in Chinese with English abstract). [刘佩佩, 白军红, 赵庆庆 等. 湖泊沼泽化与水生植物初级生产力研究进展. 湿地科学, 2013, 11(3) : 392-397.]

[24] Zhang Qi, Yuan Yijun, Mi Wujuan et al. Primary production and its influencing factors in Xiangxi River, Three-Gorges Reservoir. J Lake Sci, 2015, 27(3) :436-444(in Chinese with English abstract). DOI : 10.18307/2015.0310. [张琪, 袁 轶君, 米武娟等. 三峡水库香溪河初级生产力及其影响因素分析. 湖泊科学, 2015, 27(3):436-444.]

[25] Sun Song, Zhang Yongshan, Wu Yulin et al. Annual variation of primary productivity in Jiaozhou bay. Chinese Journal of Oceanology and Limnology, 2005, 36(6): 481-486(in Chinese with English abstract). [孙松, 张永山, 吴玉霖等. 胶 州湾初级生产力周年变化. 海洋与湖沼, 2005, 36 (6) : 481-486. ]

[26] Zhang Jialei, Zheng Binghui, Huang Minsheng et al. Seasonal variation of primary productivity in the Daning River back water area. Journal of East China Normal University (Natural Science), 2011, (1): 1-11 (in Chinese with English abstract). [张佳否, 郑丙辉, 黄民生等. 大宁河回水区初级生产力的季节变化. 华东师范大学学报 (自然科学版), $2011,(1): 1-11$.

[27] Li Rongxin, Wang Yu, Kang Jianhua et al. Temporal and spatial variations of chlorophyll a concentration and primary production in Jiulongjiang estuary waters. Journal of Oceanography in Taiwan Strait, 2011, 30(4) : 551-558(in Chinese with English abstract). [李荣欣, 王雨, 康建华等. 九龙江河口水体叶绿素 a 浓度和初级生产力的时空变化. 台湾海峡, $2011,30(4): 551-558$.

[28] Cai Linlin, Zhu Guangwei, Li Xiangyang. Characteristic of phytoplankton primary productivity and influencing factors in littoral zone of Lake Taihu. Acta Ecologica Sinica, 2013, 33(22) : 7250-7258(in Chinese with English abstract). DOI: 10.5846/stxb201207251059. [ 蔡琳琳, 朱广伟, 李向阳. 太湖湖岸带浮游植物初级生产力特征及影响因素. 生态学 报, 2013, 33(22): 7250-7258.] 